\title{
Fall prevention in nursing homes: comparison of local and international guidelines and policies: a systematic review
}

GH Yoon ${ }^{1}$, BA, RYC Kwan' ${ }^{2}$ PhD, RN, JYW Liu' ${ }^{2}$ PhD, RN, CKY Lai ${ }^{2}$ PhD, RN, FAAN

\begin{abstract}
We reviewed fall prevention guidelines and policies for nursing homes in the USA, Canada, the UK, and Australia, and compared with those in Hong Kong to identify areas for improvement.
\end{abstract}

REVIEW ARTICLE

Correspondence to: Claudia KY Lai, Honorary Professor, Centre of Gerontological Nursing, School of Nursing, The Hong Kong Polytechnic University, Yuk Choi Road, Hung Hom, Kowloon, Hong Kong SAR, China. Email: claudia.lai@polyu.edu.hk

\section{INTRODUCTION}

Falls are prevalent in nursing home settings. ${ }^{1,2}$ Falls may cause injuries such as hip, pelvic, rib, or spinal fractures. Frequent falls and the resulting injuries increase the costs for nursing homes. In the United States, $>95 \%$ of hip fractures are caused by falling, and over 2.5 million people aged $>65$ years are admitted to the emergency room after injurious falls. ${ }^{1}$ Such fractures are costly to treat and can be fatal for elderly people, especially those with chronic comorbidities such as osteoarthritis. Therefore, prevention of falls is critical for the health of nursing home residents.,4 Different countries integrate various fall prevention interventions into their clinical guidelines for nursing homes..$^{5-7}$ In Hong Kong, the standard of care for residential homes, maternity homes, and hospitals is based on the Code of Practice for Private Hospitals, Nursing Homes, and Maternity Homes. ${ }^{8}$ However, this code of practice does not cover fall risk or the fall management of elderly people, only general safety precautions.

Although many studies have been conducted on effective fall prevention interventions, to the best of our knowledge there are no studies comparing nursing home guidelines and policies among different regions. Therefore, we reviewed fall prevention guidelines and policies for nursing homes in the USA, Canada, the UK, and Australia, and compared with those in Hong Kong to identify areas for improvement.

\section{METHODS}

PubMed, JSTOR, and Google Scholar were searched for studies on fall prevention published between 2006 and 2015, using the following keywords: 'fall', 'nursing home', 'prevention'; 'program' or 'polic*'; and 'North America' or 'United States' or 'Canad" or 'Australia' or 'Brit" or 'Hong Kong'. Using the same set of keywords, a Google search was conducted to identify relevant government policies on governmental websites.

Clinical guidelines, review articles, full or partial original research articles (including interventional and observational studies), and government policy documents were included. Clinical guidelines are useful for caregivers, particularly for preventing falls. ${ }^{5}$ Review articles enable determination of the most effective fall prevention intervention. ${ }^{9}$ Interventional studies apply new or existing fall prevention interventions to unstudied populations or settings. ${ }^{10}$ Observational studies take into account various clinical and environmental variables to identify the causes of falls. ${ }^{11}$ The titles and abstracts of articles were screened. Articles were excluded if (1) they were in a language other than English; (2) they were from a source outside of academic, 
professional, governmental institutions, or nongovernmental organisations; or (3) the study sample was not representative of the general nursing home population.

For the purpose of this review, only specific policies pertaining to nursing homes were reviewed. When necessary, only subsections of larger government documents and publications were used. Relevant policies from Hong Kong, the USA, Australia, Canada, and the UK were extracted based on a systemic review of fall prevention interventions. ${ }^{9}$

\section{RESULTS}

Of 104 publications identified, 33 were reviewed, including 5 clinical guidelines, 7 review articles, 13 interventional studies, and 8 observational studies. In addition, 9 government policy documents were reviewed. Of the 33 publications, 5 were from Hong Kong, 10 from the USA, 6 from Canada, 3 from the UK, 4 from Australia, 5 from others. Of the 9 government policy documents, 2 were from Hong Kong, 2 from the USA, 1 from Canada, 2 from the UK, and 2 from Australia.

Extensive policy and guideline requirements specific to nursing home care and fall prevention were drawn from Canada. Information on the most effective fall prevention interventions were extracted from the Cochrane Review that included studies from the USA, Sweden, the Netherlands, South Korea, and Switzerland.5

\section{FALL PREVENTION INTERVENTIONS}

\section{Exercise}

Exercise improves fall risk factors rather than the fall rate..$^{12}$ In Hong Kong nursing homes, difficulties in implementing fall prevention programmes include non-compliance of residents who were unable to perceive the need for fall prevention. ${ }^{13,14}$ Compared with Western counterparts, Hong Kong elderly people are more unfamiliar with gait and balance devices and thus are more vulnerable to falls. ${ }^{13}$

In a cohort study of nursing home residents (48 in the intervention group and 51 in the control group) in Hong Kong who underwent a 36-week fall management exercise programme (12 weeks of adaptation to exercise techniques, 12 weeks of coordination exercises, and 12 weeks of balance and walking function exercises), participants were assessed for mental status, fear of falling, avoidance of activities, balance, timed up-and-go test, and history of falls in the past 1 year. ${ }^{15}$ The two groups were comparable in terms of the percentage of fallers and the number of falls. The intervention group showed significant improvement in fall risk factors such as the Berg balance scale, the 6-minute walking test, and the falls efficacy scale. However, one major limitation was that falling was not a primary outcome measure.

In a study of residents in six nursing homes in Hong Kong, 26 weeks of Tai Chi was reported to be effective in improving the quality of life of residents. ${ }^{15}$ In a study in Taichung, Taiwan, Tai Chi was reported to improve balance but had no effect on reducing the fall rate. ${ }^{16}$ The activity level of Tai Chi is equivalent to moderate-intensity exercise; the technique involves no heavy or quick physical movements. Tai Chi is popular among elderly people in Hong Kong, Taiwan, and mainland China. ${ }^{16}$

Fall risk is highest among those with a history of falls, with decreased strength and gait, or who are taking psychoactive drugs. In a systematic review of 60 randomised controlled trials of fall prevention interventions, non-pharmacological interventions were more frequently implemented than pharmacological interventions, as residents often have comorbidities that require polypharmacy, which is a major risk factor for falls. ${ }^{5}$

\section{Reducing immobility}

Hip protectors promote ambulation with reduced risk of hip fractures in case of falling and thus are effective in preventing injurious falls; however, they do not reduce the fall rate in institutionalised settings such as nursing homes. ${ }^{17}$ In addition, hip protectors are poorly utilised by nursing home residents and staff. $^{14}$

Sedentary activities are defined as activities that do not increase energy expenditure. ${ }^{18}$ In a Swedish study on immobility among nursing home residents, an average of $75 \%$ of the waking hours of all ambulatory residents were spent in sedentary activities such as reading, watching television, listening to music, and talking on the phone, owing to a lack of external motivators or facilities. ${ }^{18,19}$ 
Active ambulation exercises that break the habit of sedentary behaviour can promote fall prevention, prevent pressure sores, and improve the mental status of residents by providing more stimuli in their daily routine. ${ }^{18}$

In a study of 175 French nursing homes involving 6275 residents, $70 \%$ of residents had mobility disability and $80 \%$ had some degree of functional disability in terms of activities of daily living (ADLs) ${ }^{20}$ Although there is limited evidence to suggest a strong correlation between sedentary behaviour and falls, a study in western Canada involving 46 residents reported that more sit-to-stand exercise was associated with improved mobility. ${ }^{21}$

\section{Promoting ambulation}

The most notable effects of falls are decreased motivation, physical and social activity, and level of mobility. ${ }^{1}$ Ambulatory interventions help maintain or increase daily activity and require residents to stand up, walk, and sit down with minimal use of their hands under caregiver supervision. ${ }^{19}$ These interventions are controversial, because standing up slowly, sitting, and walking forward are the three main causes of falls in residential homes. ${ }^{22}$ However, falls occur when these actions are taken by residents without any supervision. ${ }^{23}$ Safety assessment (such as the up-and-go test) should be performed prior to ambulatory intervention. ${ }^{24}$

Four urban nursing homes in New York demonstrated that minimising the use of restrictive side rails and implementing advanced nursing practice for safety significantly decreased the fall rate among the $51.4 \%$ of residents who voluntarily reduced or completely stopped using side rails. ${ }^{25}$ Residents who continued to use the rails had no significant change in fall rate.

\section{Level of care}

In a study of 15 nursing home facilities in Korea, more hours of care by registered nurses rather than personal care workers was related to a $6.8 \%$ decrease in fall rate at 3 months. ${ }^{26}$ This is attributed to increased registered nurse training in fall prevention, as well as raising awareness among personal care workers and lower-level support staff.

\section{Multifactorial interventions}

Multifactorial programmes in fall prevention aim to reduce predisposing and situational fall risk caused by the environment and the behaviour of nursing home residents. ${ }^{27}$ Multifactorial programmes include fall prevention education, hazard assessment, and medication review. ${ }^{27} \mathrm{~A}$ meta-analysis of fall prevention methods over 10 years indicated that multifactorial interventions were $10 \%$ more successful than non-multifactorial interventions. ${ }^{9}$

In a qualitative study in Minnesota, as a part of a multi-facility fall reduction programme involving 13 nursing home facilities, participants suggested areas of improvement, including organisational flexibility; three-way communication among patients, families, and staff; and communication with staff to create individualised fall prevention plans. ${ }^{28}$

A staff education programme (CONNECT) was implemented in four nursing homes involving 497 staff in Durham, North Carolina. ${ }^{29}$ The programme used a social constructivist learning process that included storytelling, relationship mapping, mentoring, self-monitoring, and feedback. The fall reduction education programme included more practical interventions such as group training, modules, teleconferences, academic detailing, and audits and feedback on skills. The CONNECT programme was used to measure the effects of strengthened communication between nursing home staff members. Staff perceptions significantly improved in terms of quality of communication, participation in decision-making, climate of safety, and caregiving quality, and in the use of local interaction strategies. ${ }^{29} \mathrm{~A}$ follow-up study 1 year later showed that staff in the CONNECT programme had a better communication system and communicated more frequently and were able to devise more creative fall prevention interventions. ${ }^{30}$

In a Cochrane review of 4512 participants in four trials, ${ }^{5}$ increasing vitamin D intake results in a significant decrease in the fall rate but not the fall risk. ${ }^{14}$ In another Cochrane review, vitamin D supplementation was found to be effective in reducing the fall rate, but the effect of exercise or multifactorial interventions in care facilities on reducing the fall rate was uncertain, owing to wide variations in study design. ${ }^{5}$ Multifactorial interventions supervised by a single disciplinary team did not result in a significant reduction in fall rate or fall risk. ${ }^{19}$ In contrast, in a post-hoc subgroup analysis of 1651 participants, 
significant reductions in fall rate and fall risk were noted when multifactorial interventions were carried out by a multidisciplinary team. ${ }^{19}$

\section{FALL PREVENTION POLICIES}

We compared policies from the USA, ${ }^{31,32}$ Canada, ${ }^{6}$ the UK, $, 33,34$ Australia, ${ }^{7,35}$ and Hong Kong ${ }^{8,36}$ to identify areas of improvement for residential homes and long-term care facilities in Hong Kong, while considering cultural differences (TABLE).

\section{Fall prevention programme}

Only the UK and Canada require implementation of fall prevention programmes in nursing homes. All regions promote efforts to prevent falls by preventing declines in ADL, cognitive, and mobility levels. The UK encourages resident participation in daily chores and daily exercises. Nursing home staff in the UK are trained to deliver diverse and enjoyable activities. Rehabilitative care is also mentioned as part of the restorative care to maintain or improve general motor and mental function. In Hong Kong, the Code of Practice for Private Hospitals, Nursing Homes, and Maternity Homes briefly mentions restorative care, the minimum number of hours for basic nursing care, personal care, and restorative exercises. However, guidelines on restorative care measures are lacking in detail compared with equivalent guidelines from other regions.

\section{Facility requirements}

There are requirements for bedside, toilet, shower, corridor, lighting, and common-area facilities in the USA, Canada, the UK, and Australia but not in Hong Kong. The US and the UK specify the minimum amount of space to be allotted for each resident depending on the setting and whether in the personal/shared room or in the common area. There are also specifications for railings along corridors, beds, and washing and toileting areas to prevent falls and facilitate ambulation of residents. Hong Kong only mandates regular maintenance of equipment designated for the residents, and provision of supplies appropriate to the needs and services offered by the home. Specification on railings is stated in most institutions such as nursing and long-term care home facilities.

\section{Assessment requirements}

The UK had the most assessment requirements for residents. Initial assessment is conducted to determine a personalised care plan for a resident. Subsequently there is a monthly fall risk assessment and mandatory review/revision of the care plan. Canada requires a customised bed area for each resident according to the results of fall risk assessment. In the UK and Canada, initial assessment for new admissions include the resident's cognitive, psychosocial, visual, and musculoskeletal health. In Hong Kong, the Code of Practice for Private Hospitals, Nursing Homes, and Maternity Homes mentions the need to conduct regular assessments for residential home residents but does not specify the extent of the assessments or specific criteria for nursing home residents.

\section{Pharmacology management}

All five regions have requirements to stop or control medications after they no longer appear to be necessary or effective. The USA and Canada specify regulations for the use of psychoactive drugs. Canada requires a quarterly evaluation of the regimen of each resident, whereas the USA requires a monthly evaluation. The USA suggests dosage minimisation with behavioural interventions. In Hong Kong, the UK, and Australia, requirements for regular assessment of residents' drug regimens are lacking. Nonetheless, Hong Kong stresses the need to keep records on dosage, date and time of administration, and any error/near-miss during drug administration.

\section{POLICY AND PRACTICE GUIDELINE SUGGESTIONS FOR HONG KONG}

Hong Kong has no policy exclusively for residential homes, only a combination of standards that apply to residential homes along with maternity homes and private hospitals. There is also no policy specifically for preventing injurious falls, although many policies mention prevention of injuries. Hong Kong lacks policies for residential homes in terms of facilities management and care implementation.

Policies should be implemented to increase aid for resident ambulation, including adding specifications on railings in different settings, increased personal space, and more comprehensive assessments related to fall risk. Future policies on nursing homes must address the lack of space in nursing facilities, as this contributes to a decline in quality of care and an increase in fall risk. ${ }^{36,37}$ Policies on restorative 
TABLE

Fall prevention policies of the USA, ${ }^{30,31}$ Canada, ${ }^{6}$ the UK, ${ }^{32,33}$ Australia, ${ }^{7,35}$ and Hong Kong ${ }^{8,36}$

Region Fall prevention policy

\section{Facilities}

US $\quad$ - Bedrooms must contain no more than four residents and provide at least $80 \mathrm{sq} f \mathrm{ft}$ per resident in a multi-resident room and $100 \mathrm{sq} f \mathrm{ft}$ in a single-resident room.

- Each room must be equipped with or near to toilet and bathing facilities.

- Corridors must be equipped with handrails on each side.

- Dining and activity rooms should be well lit, ventilated, furnished, and have sufficient space.

Canada - A bedside table is required for each resident.

- Every resident shower must have at least two easily accessible grab bars: at least one bar must be located on the same wall as the faucet, and another on the adjacent wall.

- Lighting requirements for all enclosed stairways, corridors, and all other areas of the home, as well as by the bed of each resident when the bed is set at a reading position.

- Bed rails are used if deemed necessary after assessment.

UK - All accommodation for a resident must be provided in a single bedroom unless otherwise requested.

- Each resident must be allotted a minimum of $12 \mathrm{~m}^{2}$ of bedroom space; if disabled, $20 \mathrm{~m}^{2}$.

- The minimum ceiling height is $2.4 \mathrm{~m}$.

- Handrails are required in all bath and shower facilities.

- There are other specifications to ensure that residents have enough communal, toilet, shower, and bedroom space.

- Lighting must allow for increased light levels. Motion sensor lighting may be used in bathrooms and corridors.

- Sudden changes in light levels must be avoided. Natural daylight should be utilised wherever possible.

Australia - Over-bed tables must be provided for every bed.

- Bed rails, ripple mattresses, and bedding to fit a resident's extended needs must be provided.

- Items to assist with toileting and incontinence management, such as commode chairs, urinal covers, over-toilet chairs, shower chairs, and uridomes must be provided.

Hong - Any equipment designated for resident use should be maintained at regular intervals.

Kong - Sufficient equipment and supplies appropriate to the needs and services offered by the home must be provided.

\section{Physical and mental assessments}

US - A full assessment must be conducted for residents within 14 days of admission.

- Regular assessments must be conducted no less than once per year.

- Facilities must use a state-specified Resident Assessment Instrument for regular assessments of cognitive patterns, vision, psychosocial well-being, physical functioning, activity pursuit, and medications.

Canada - For every long-term care home where bed rails are used, the resident must be assessed and the resident's bed system must be evaluated in accordance with evidence-based practices.

- The height and latch reliability of rails must be tested regularly.

- Plan of care must stem from an interdisciplinary assessment of the resident's cognitive ability, vision, mental health, daily activity patterns, drug treatments, and existing risks and interventions.

- The home must ensure that the plan of care is reviewed and revised each time the resident is reassessed.

UK - The initial plan of care based on the pre-admission assessment and referral information must be in place within 24 hours of admission.

- A detailed plan of care for each resident must be generated from a comprehensive assessment.

- Assessment is commenced on the day of admission and completed within 5 days of admission.

- Assessment of fall risk must be carried out, using an accepted risk assessment poll, no later than 24 hours after admission.

- If the resident is deemed to be at risk of falling, a detailed fall care plan is put in place following the risk assessment. This is fully documented and communicated.

- The fall risk assessment must be updated no less frequently than monthly, and the care plan must also be amended accordingly.

- Falls must be reviewed and analysed monthly to identify any patterns or trends and to determine the appropriate action to be taken.

Australia - Initial assessment and care planning must be carried out by a nurse practitioner or registered nurse, and ongoing management and evaluation are carried out by a nurse practitioner, registered nurse, or enrolled nurse.

- Each resident must participate in an appropriate needs assessment.

- Each resident's needs must be monitored and regularly reassessed, taking into account any relevant programme guidelines and in accordance with the complexity of the resident's needs.

Hong - For elderly people living in nursing homes on a long-term basis, regular assessments must be undertaken by medical

Kong practitioners and allied health care professionals.

\section{Post-fall assessment}

US - Residents must be assessed within 14 days of any incident that may have caused physical or mental harm.

Canada - Every licensee of a long-term care home must ensure that when a resident has fallen, the resident is assessed and that where the condition or circumstances of the resident require, a post-fall assessment is conducted using a clinically appropriate assessment instrument that is specifically designed for falls.

UK - A post-fall review must be carried out within 24 hours of the incident to determine the reason for the fall and subsequent preventative measures. This is in addition to existing regulations regarding the recording of the incident within the home.

- The resident's care plan must be amended accordingly. 


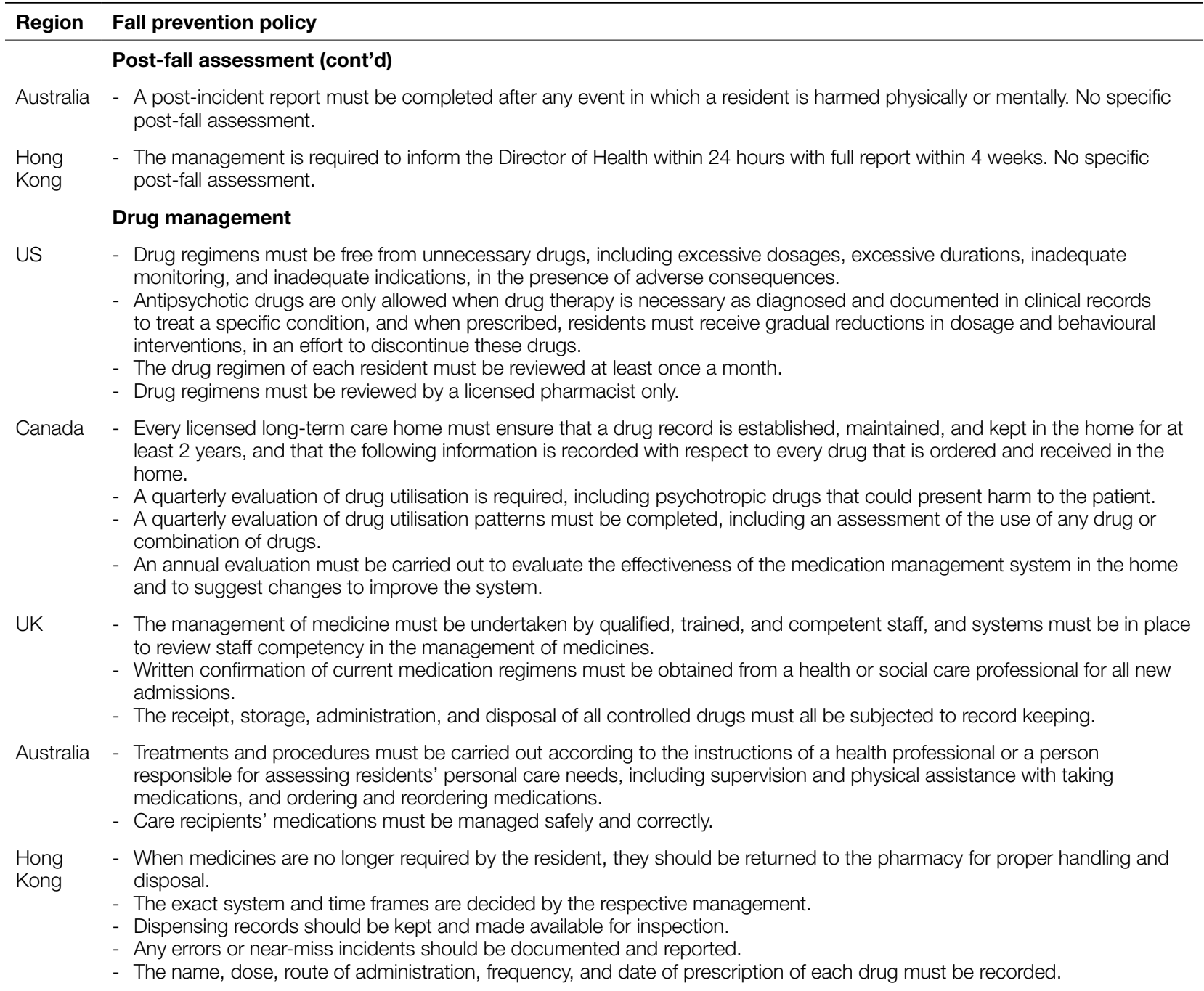

\section{Accident management}

US - Homes must ensure that the environment remains as free as possible from accident hazards and that each resident receives adequate supervision and assistance devices to prevent accidents.

- The nurses' station must be equipped to receive resident calls through a communication system from the residents' rooms and from toilet and bathing facilities.

Canada - Homes must ensure that mobility devices (wheelchairs, walkers, and canes) are available at all times to residents who require them on a short-term basis.

- Doors must have a door access control system, which must always be on, an audible door alarm connected to the resident-staff communication and response system, and also to an audio-visual enunciator connected to the nurses' station with a manual reset switch at the door.

UK - Mobility devices including crutches, quadruped walkers, walking frames, walking sticks, and wheelchairs must be available to residents at all times.

- This also includes mechanical devices for lifting residents, such as stretchers and trolleys.

- Fire, security, and other emergency management staff and home staff must actively work to provide safe systems that minimize fire, security, and emergency risks.

Australia - Furniture must be arranged with enough space to not impose barriers or obstacles to movement and to encourage communication among residents. Effective signage, appropriately positioned, will help residents to find their way.

- Any mirrors that may present confusion to the resident must be covered.

- Assistive technologies must be used to promote non-intrusive monitoring at night where appropriate.

- Staff must be trained in, and able to demonstrate, how to understand effective and appropriate risk assessment and management.

Hong - An emergency call system must be available to call for assistance.

Kong - Comprehensive written risk management policies and supporting procedures must cover the assessment of risk throughout the process of establishing, identifying, analysis, and learning from adverse health events or near-misses, and in devising arrangements for responding to emergencies (fire evacuation, flooding, and electrical emergencies).

- One person should be appointed to coordinate risk assessments and promulgate information on identifying risks and providing solutions. 


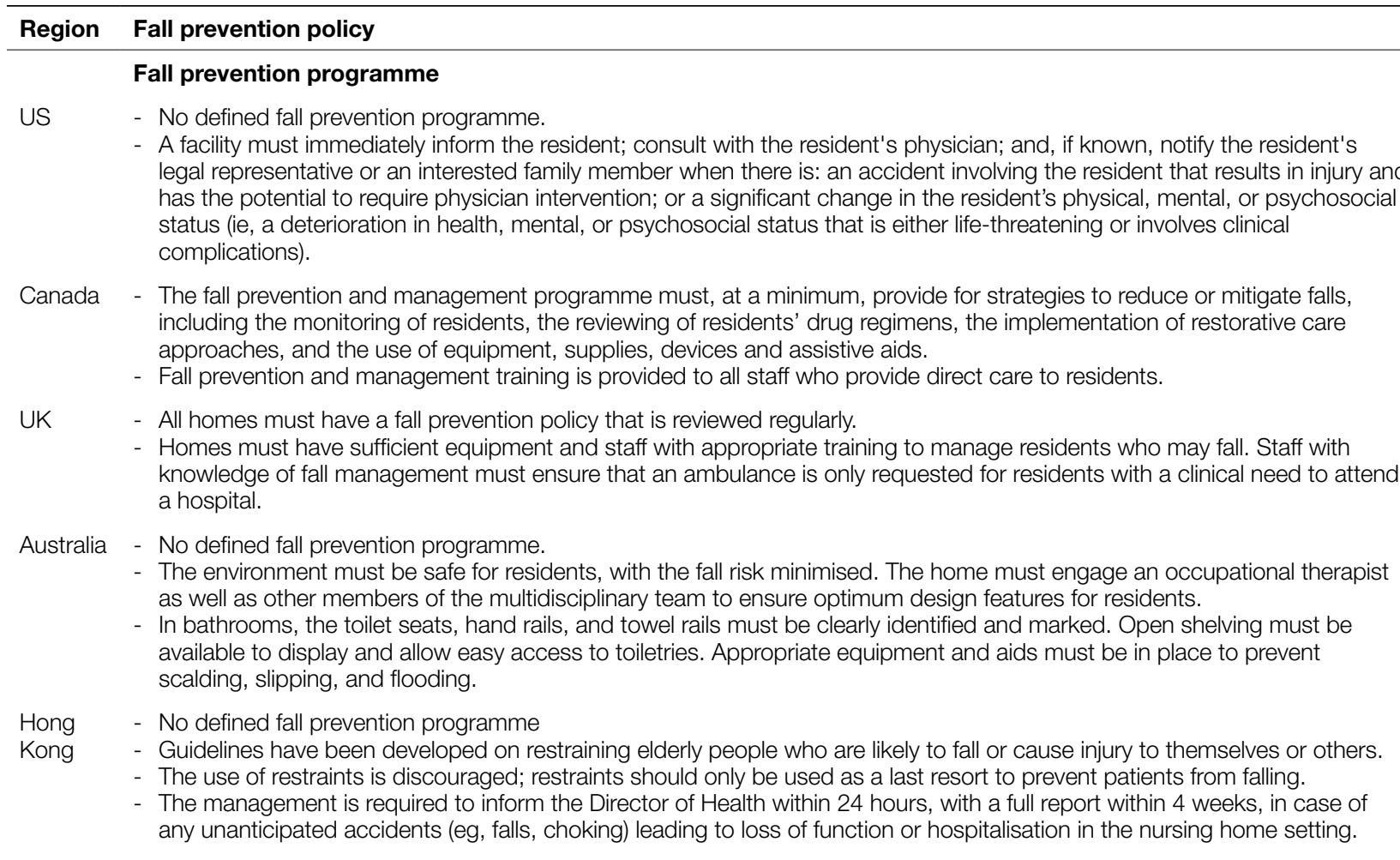

\section{Nursing and medical care}

US - The nurses' station must be equipped to receive calls from every room and from all toilet and bathing facilities.

- Residents must be seen by a physician at least once every 30 days for the first 90 days after admission, and at least once every 60 days thereafter.

- Treatment is considered timely if a visit occurs no later than 10 days after the required date of the visit.

Canada - At least one registered nurse must be on duty at all times.

- The facility must ensure that each resident receives individualised personal care, including daily hygiene care and grooming.

UK - Appointments should be made at least annually, in accordance with individual requirements.

- Information on personal health care should include information on skin care, continence, level of physical activity, and mental well-being.

- All residents must have a named nurse who has responsibility for discussing, planning, and agreeing to the nursing interventions that are necessary to meet the residents' assessed needs. This must be done in partnership with the residents and their relatives.

Australia - Treatments and procedures must be carried out in accordance with the instructions of a health care professional or a person responsible for assessing a resident's personal care needs.

- Personal assistance, including individual attention, individual supervision, and physical assistance must be provided to residents with cognitive impairment (ie, dementia and other cognitive disorders).

Hong - A home that does not provide 24-hour resident medical practitioner coverage must inform the resident and the next of kin

Kong of this before admission.

- At least one medical practitioner who is competent in emergency medicine must be on duty during operating hours to provide accident and emergency services.

\section{Therapy}

US - The activities programme must be directed by a professional who is a qualified therapeutic recreation specialist, who is a qualified occupational therapist or therapy assistant, or who has completed a therapy training course approved by the State.

- If specialised rehabilitative services such as, but not limited to, physical therapy, speech-language pathology, occupational therapy, and mental health rehabilitative services, are required as part of a resident's plan of care, the facility must provide the required services, or obtain them from an outside resource.

Canada - The facility must ensure that on-site physiotherapy is provided in individual or group settings, based on preference and assessed care needs, as well as occupational therapy and speech-language therapy.

UK

- The home must provide a programme of active rehabilitation involving the contribution of all necessary interventions such as, but not limited to, occupational therapy, speech and language therapy, or physiotherapy to enable the resident to return home. 


\begin{tabular}{|c|c|}
\hline Region & Fall prevention policy \\
\hline & Therapy (cont'd) \\
\hline Australia & $\begin{array}{l}\text { - Assistance must be given in obtaining access to specialized therapy services as needed, including physiotherapy. } \\
\text { - Care should include individual therapy activities and specific programmes to treat a specific condition as needed. } \\
\text { - The facility must provide recreational therapy suited to the residents and encourage residents to participate in these } \\
\text { activities and to use communal recreational equipment. } \\
\text { - Therapy services should include recreational, speech therapy, podiatry, occupational, and physiotherapy services. } \\
\text { - More intensive therapy must be delivered by health professionals or care staff as directed by health professionals, on a } \\
\text { temporary basis, that is designed to allow residents to reach a level of independence at which maintenance therapy will } \\
\text { meet their needs. }\end{array}$ \\
\hline \multirow{2}{*}{$\begin{array}{l}\text { Hong } \\
\text { Kong }\end{array}$} & - A registered physiotherapist responsible for training all support staff must be assigned to each home. \\
\hline & Restorative care \\
\hline US & $\begin{array}{l}\text { - The facility must provide for an ongoing programme of activities designed to meet, in accordance with the comprehensive } \\
\text { assessment, the interests and physical, mental, and psychosocial well-being of each resident. } \\
\text { - Based on the comprehensive assessment at the time of admission, the facility must ensure that the resident's activities of } \\
\text { daily living level do not diminish, unless the resident's clinical condition points to unavoidable diminution. }\end{array}$ \\
\hline Canada & $\begin{array}{l}\text { - In addition to the fall prevention management programme, restorative care approaches must be integrated into the care } \\
\text { plan of all residents. These approaches must be coordinated to ensure that residents are able to maintain or improve } \\
\text { functional and cognitive capacity in all aspects of living to the extent of their abilities. } \\
\text { - The facility must ensure that staff use devices and techniques that maintain or improve residents' weight-bearing ability, } \\
\text { endurance, and range of motion. }\end{array}$ \\
\hline UK & $\begin{array}{l}\text { - Care plans must clearly demonstrate the promotion of maximum independence and rehabilitation, and take into account } \\
\text { the advice and recommendations from relevant health and social care professionals. } \\
\text { - Residents should be encouraged to participate in the daily chores within the home. } \\
\text { - Opportunities should be given for engaging in appropriate exercise and physical activities. } \\
\text { - Staff should understand how to deliver appropriate and enjoyable activities and events for residents. }\end{array}$ \\
\hline Australia & $\begin{array}{l}\text { - Rehabilitation support refers to individual therapy programmes designed by health professionals that are aimed at } \\
\text { maintaining or restoring a resident's ability to perform daily tasks for himself or herself, or at assisting residents to obtain } \\
\text { access to such programmes. } \\
\text { - Maintenance therapy delivered by health professionals or care staff as directed by health professionals, is designed to } \\
\text { maintain residents' levels of independence in activities of daily living. }\end{array}$ \\
\hline $\begin{array}{l}\text { Hong } \\
\text { Kong }\end{array}$ & $\begin{array}{l}\text { - Homes must provide residents, considering their level of frailty and disability, with a minimum number of hours of direct care } \\
\text { services including basic and special nursing care, personal care, and restorative and maintenance rehabilitation exercises. }\end{array}$ \\
\hline
\end{tabular}

care may prevent decline in ADLs, ambulation, and cognitive levels of nursing home residents. Institutional policies overseeing the frequency and quality of environment hazard assessments, reeducating staff in fall risk and fall prevention, and physical assessments for each resident may decrease fall risks and fall rates.

Improving the education of personal care workers and nursing assistants directly affects the quality of care of the residents. Regular assessments of facilities to promote safe ambulation of residents should be implemented. ${ }^{3}$ Preventing a sedentary lifestyle by offering a diverse choice of activities may extend the resident's ability to carry out $\mathrm{ADLs}^{18}{ }^{18}$ as immobility decreases the use of the lower-extremity muscles and increases the fall risk. Activities should be individualised for each resident's ADL needs. ${ }^{21}$ This promotes focused care suited to the activity levels of the individual. Providing ample opportunities for physical activity is crucial to preventing falls and improving the general mental and physical health of residents. ${ }^{1,26,38}$ The adherence rate to exercise programmes is high in Hong Kong when residents have an increased sense of belonging and peer support. ${ }^{15}$ Preventative exercises suited to residents such as Tai Chi, dances, breathing exercises, and movement exercises, should be offered and regulated to ensure that necessary resources are provided and that such programmes are implemented effectively. ${ }^{39}$

Updating evidence-based guidelines and educating nurses improves fall prevention for nursing home residents. In a 2011 survey on guideline development in various institutions around the world, most respondents reported difficulties in implementation owing to inefficient internal procedures and lack of resources. ${ }^{40}$ Efforts should 
be made to adopt international guidelines for Hong Kong nursing home residents through stakeholder engagement in the local community. Prioritisation of recommendations through stakeholder feedback is effective guideline implementation, along with consultation of clinical relevance with clinicians and assessment of the local health care economy. ${ }^{41}$

\section{LIMITATIONS}

The cultural background of Hong Kong may differ from that of Western countries and result in differences in policy and practice. It was difficult to find policies specific to nursing home care and facilities; as such, policies were often contained in subsections of broader health-related policies.

\section{CONCLUSION}

Nursing homes around the world have limitations in their efforts to monitor and secure residents on a round-the-clock basis. ${ }^{42}$ These limitations include a lack of compliance on the part of residents, ${ }^{14,16}$ and failure to implement safety measures, document the fall risk, and devise intervention plans in a timely manner on the part of staff. ${ }^{43}$ Insufficient resources and a lack of guidelines specific to nursing homes may result in substandard health care practices, increasing the fall risk and other risk factors for residents. ${ }^{44,16}$ Facility-level multifactorial programmes implemented by a multidisciplinary team may lead to reductions in fall rate and fall risk. ${ }^{14}$ Individual interactions between personal care workers and residents should be encouraged and focused towards increasing resident participation in ambulation exercises and ADL levels. ${ }^{24}$ Enhancing community and facility-wide education about the importance of preventing falls by vigilant medication review and adequate vitamin D administration should be included in Hong Kong fall prevention programmes. ${ }^{5}$ It would be beneficial for caregivers, health care professionals, and policy makers to establish a standard of care for fall prevention and fall management in nursing homes.

\section{ACKNOWLEDGMENTS}

We wish to thank the Hong Kong Polytechnic University's School of Nursing and Northeastern University for providing an international research internship position, resources to gather data, and the invaluable mentorship necessary to complete this manuscript. We would like to acknowledge the Yuen Yuen Institute for facilitating the search of local information in Hong Kong.

\section{DECLARATION}

The authors have no conflict of interest to disclose.

\section{REFERENCES}

1. US Centers for Disease Control and Prevention. Falls among Older Adults: An Overview. US Department of Health \& Human Services; 2015.

2. Luk JK, Chan TY, Chan DK. Falls prevention in the elderly: translating evidence into practice. Hong Kong Med J 2015;21:16571. Crossref

3. Tinetti ME, Baker DI, King M, et al. Effect of dissemination of evidence in reducing injuries from falls. $N$ Engl J Med 2008;359:252-61. Crossref

4. Quigley PA, Campbell RR, Bulat T, Olney RL, Buerhaus P, Needleman J. Incidence and cost of serious fall-related injuries in nursing homes. Clin Nurs Res 2012;21:10-23. Crossref

5. Cameron ID, Gillespie LD, Robertson MC, et al. Interventions for preventing falls in older people in care facilities and hospitals. Cochrane Database Syst Rev 2012;12:CD005465. Crossref

6. Ontario Regulation Title 79, Sec 10. Long-Term Care Homes Act of 2007.

7. Quality of Care principle 2014 Schedule 1, Parts 2 and 3 (AU). Care and Services for Residential Care Services.

8. Hong Kong Department of Health. Code of Practice for Private Hospitals, Nursing Homes, and Maternity Homes. April 2010.

9. Choi M, Hector M. Effectiveness of intervention programs in preventing falls: a systematic review of recent 10 years and metaanalysis. J Am Med Dir Assoc 2012;13:188.e13-21. Crossref

10. Nitz J, Cyarto E, Andrews S, et al. Outcomes from the implementation of a facility-specific evidence-based falls prevention intervention program in residential aged care. Geriatr Nurs 2012;33:41-50. Crossref

11. Yang Y, Feldman F, Leung PM, Scott V, Robinovitch SN. Agreement between video footage and fall incident reports on the circumstances of falls in long-term care. J Am Med Dir Assoc 2015;16:388-94. Crossref

12. Wong EL, Woo J, Cheung AW, Yeung PY. Determinants of participation in a fall assessment and prevention programme among elderly fallers in Hong Kong: prospective cohort study. J Adv Nurs 2011;67:763-73. Crossref

13. Kenny RA, Ni Scanaill C, McGrath M. Falls Prevention in the Home: Challenges for New Technologies. Available from: http:// www.rand.org/content/dam/rand/www/external/labor/aging/rsi/ rsi_papers/2012/kenny2.pdf. Accessed [date???].

14. Korall AM, Feldman F, Scott VJ, et al. Facilitators of and barriers to hip protector acceptance and adherence in long-term care facilities: a systematic review. J Am Med Dir Assoc 2015;16:18593. Crossref

15. Yeung PY, Chan W, Woo J.A community-based Falls Management Exercise Programme (FaME) improves balance, walking speed and reduced fear of falling. Prim Health Care Res Dev 2015;16:13846. Crossref

16. Lee LY, Lee DT, Woo J. The psychosocial effect of Tai Chi on nursing home residents. J Clin Nurs 2010;19:927-38. Crossref

17. Santesso N, Carrasco-Labra A, Brignardello-Petersen R. Hip protectors for preventing hip fractures in older people. Cochrane Database Syst Rev 2014;3:CD001255. Crossref 
18. de Souto Barreto P. Non-pharmacological interventions in the nursing home setting: does it make any sense to struggle against sedentary behavior among residents? J Nurs Home Res 2015;1:524.

19. Gillespie L, Handoll H. Prevention of falls and fall-related injuries in older people. Inj Prev 2009;15:354-5. Crossref

20. de Souto Barreto P, Lapeyre-Mestre M, Mathieu C, et al. A multicentric individually-tailored controlled trial of education and professional support to nursing home staff: research protocol and baseline data of the IQUARE study. J Nutr Health Aging 2013;17:173-8. Crossref

21. Slaughter SE, Estabrooks CA. Optimizing the mobility of residents with dementia: a pilot study promoting healthcare aide uptake of a simple mobility innovation in diverse nursing home settings. BMC Geriatr 2013;13:110. Crossref

22. Silva RB, Eslick GD, Duque G. Exercise for falls and fracture prevention in long term care facilities: a systematic review and meta-analysis. J Am Med Dir Assoc 2013;14:685-9.e2. Crossref

23. Low LF, Fletcher J, Goodenough B, et al. A systematic review of interventions to change staff care practices in order to improve resident outcomes in nursing homes. PLoS One 2015;10:e0140711. Crossref

24. Ambrose AF, Cruz L, Paul G. Falls and fractures: a systematic approach to screening and prevention. Maturitas 2015;82:8593. Crossref

25. Capezuti E, Wagner LM, Brush BL, Boltz M, Renz S, Talerico KA. Consequences of an intervention to reduce restrictive side rail use in nursing homes. J Am Geriatr Soc 2007;55:334-41. Crossref

26. Shin JH, Hyun TK. Nurse staffing and quality of care of nursing home residents in Korea. J Nurs Scholarsh 2015;47:555-64. Crossref

27. Cusimano MD, Kwok J, Spadafora K. Effectiveness of multifaceted fall-prevention programs for the elderly in residential care. Inj Prev 2008;14:113-22. Crossref

28. Abrahamson K, Davila H, Mueller C, Inui T, Arling G. Examining the lived experience of nursing home quality improvement: the case of a multifacility falls reduction project. J Gerontol Nurs 2013;39:24-30. Crossref

29. Colon-Emeric CS, McConnell E, Pinheiro SO, et al. CONNECT for better fall prevention in nursing homes: results from a pilot intervention study. J Am Geriatr Soc 2013;61:2150-9. Crossref

30. Colón-Emeric CS, Pinheiro SO, Anderson RA, et al. Connecting the learners: improving uptake of a nursing home educational program by focusing on staff interactions. Gerontologist 2014;54:446-59. Crossref

31. US Policy Title 42, Part 483, Subpart B. Requirements for Long-Term Care Facilities. 2011.

32. US Federal Government 42 CFR §483. Nursing Home Reform Act. 2014.

33. Legislative Counsel Office of Prince Edward Island Cap. C-13, Sec 13. Nursing Home Regulations. 8 November 2005.

34. UK Department of Health, Social Services, and Public Safety. Care Standards for Nursing Homes. 2015.

35. Office of Parliamentary Counsel, Canberra No.112, 1997, Compilation No. 55. Aged Care Act of 1997. 24 September 2015.

36. Hong Kong Legislative Council LC Paper N. CB(2)643/13-14(01). Integrated Home Care Services for the Elderly. 14 January 2014.

37. Lai PC, Low CT, Wong M, Wong WC, Chan MH. Spatial analysis of falls in an urban community of Hong Kong. Int J Health Geogr 2009;8:14. Crossref

38. Moncada LV. Management of falls in older persons: a prescription for prevention. Am Fam Physician 2011;84:1267-76.

39. Teresi JA, Ramirez M, Remler D, et al. Comparative effectiveness of implementing evidence-based education and best practices in nursing homes: effects on falls, quality-of-life and societal costs. Int J Nurs Stud 2013;50:448-63. Crossref

40. Alonso-Coello P, Martínez García L, Carrasco JM, et al. The updating of clinical practice guidelines: insights from an international survey. Implement Sci 2011;6:107. Crossref

41. Richter-Sundberg L, Kardakis T, Weinehall L, Garvare R, Nyström ME. Addressing implementation challenges during guideline development: a case study of Swedish national guidelines for methods of preventing disease. BMC Health Sero Res 2015;15:19.. Crossref

42. Bell JL, Collins JW, Tiesman HM, et al. Slip, trip, and fall injuries among nursing care facility workers. Workplace Health Saf 2013;61:147-52. Crossref

43. Wagner LM, Dionne JC, Zive JR, Rochon PA. Fall risk care processes in nursing home facilities. J Am Med Dir Assoc 2011;12:426-30. Crossref

44. Burland E, Martens P, Brownell M, Doupe M, Fuchs D. The evaluation of a fall management program in a nursing home population. Gerontologist 2013;53:828-38. Crossref 